\title{
PENGARUH STRATEGI PEMBELAJARAN KOOPERATIF DAN TINGKAT KOMUNIKASI INTERPERSONAL TERHADAP HASIL BELAJAR PENDIDIKAN KEWARGANEGARAAN (PKn)
}

\author{
Jamilah \\ Sekolah Dasar Negeri 116881 Torgamda, Sumatera Utara \\ jamilahnst65@gmail.com
}

\begin{abstract}
Abstrak: Tujuan penelitian adalah: mengetahui hasil belajar Pendidikan Kewarganegaraan (PKn) siswa yang dibelajarkan dengan menggunakan strategi pembelajaran kooperatif tipe STAD dan hasil belajar PKn siswa yang dibelajarkan dengan strategi pembelajaran ekspositori, mengetahui hasil belajar PKn antara siswa dengan tingkat komunikasi interpersonal tinggi dengan hasil belajar siswa dengan komunikasi interpersonal rendah, mengetahui interaksi antara strategi pembelajaran dan komunikasi interpersonal terhadap hasil belajar PKn. Populasi penelitian adalah siswa Sekolah Dasar Negeri 116881 Torgamda dengan Teknik penarikan sampel dilakukan dengan cluster random sampling. Metode penelitian yang menggunakan metode quasi eksperimen dengan desain penelitian faktorial $2 \times 2$. Teknik analisis data menggunakan ANAVA dua jalur pada taraf signifikansi $\alpha=0,05$. Hasil penelitian menunjukkan bahwa: Hasil belajar PKn siswa dengan strategi pembelajaran kooperatif STAD lebih baik dibandingkan dengan strategi pembelajaran Ekspositori. Hasil belajar siswa yang memiliki komunikasi interpesonal tinggi lebih baik dibandingkan dengan hasil belajar siswa yang memiliki komunikasi interpersonal rendah. Terdapat interaksi antara strategi pembelajaran dengan komunikasi interpersonal dalam mempengaruhi hasil belajar $P K n$.
\end{abstract}

Kata Kunci: strategi pembelajaran, tipe STAD, ekspositori, pendidikan kewarganegaraan

\begin{abstract}
The research objectives are: knowing the learning outcomes of Civics Education students who are taught using STAD type cooperative learning strategies and student Civics learning outcomes that are taught with expository learning strategies, knowing the Civics learning outcomes between students with high levels of interpersonal communication with learning outcomes students with low interpersonal communication, knowing the interaction between learning strategies and interpersonal communication on Civics learning outcomes. The study population was 116881 Torgamda State Elementary School students with the sampling technique carried out by cluster random sampling. The research method that uses a quasi-experimental method with a $2 \times 2$ factorial research design. Data analysis techniques using two-way ANOVA at a significance level $\alpha=0.05$. The results showed that: Student learning outcomes Civics with STAD cooperative learning strategies are better than Expository learning strategies. The learning outcomes of students who have high interpersonal communication are better than the learning outcomes of students who have low interpersonal communication. There is an interaction between learning strategies with interpersonal communication in influencing Civics learning outcomes.
\end{abstract}

Keywords: learning strategies, STAD type, expository, citizenship education

\section{PENDAHULUAN}

Berbicara masalah kualitas dan pengembangan potensi agar peserta didik berilmu, cakap dan kreatif tidak terlepas dari masalah pengajaran karena pengajaran merupakan inti dari proses pendidikan. Peningkatan kualitas pendidikan menunjuk pada upaya peningkatan kualitas proses dan hasil pengajaran. Agar kualitas pengajaran bermutu dari segi proses, maka cara pembelajaran sangat mempengaruhi efektifitas proses belajar mengajar. Untuk mendapatkan Sumber Daya Manusia (SDM) yang berkualitas, yang mampu bersaing, diperlukan guru dan tenaga kependidikan yang memiliki strategi yang mantap. Guru dan tenaga kependidikan tersebut perlu dibina dan dikembangkan dan diberi penghargaan yang layak. Hal ini penting terutama jika dikaitkan dengan berbagai kajian yang menentukan keberhasilan pendidikan dan meningkatkan kualitas pembelajaran, serta membentuk kompetensi harus menempatkan siswa sebagai titik sentral. Pengalaman menunjukkan bahwa guru masih sering mengabaikan penerapan berbagai strategi mengajar pada waktu berinteraksi dengan siswa khususnya mata pelajaran PKn , siswa menerima apa adanya. Padahal guru sebagai tenaga pengajar telah dibekali dengan berbagai keterampilan 
mengajar yang tujuannya agar memberi kesempatan bagi terjadinya kadar lebih tinggi keterlibatan dan prakarsa siswa dalam belajar. Hal ini didukung oleh Gagne (1988) yang mengemukakan bahwa konsep pengajaran merupkan seperangkat peristiwa untuk mempengaruhi siswa agar belajar.

PKn adalah pendidikan kewarganegaraan tentang nilai-nilai yang sasarannya bukan semata-mata pengalihan pengetahuan melainkan lebih ditekankan pada pembentukan sikap menjadikan warganegara yang baik dan bermartabat. Dengan demikian, mata pelajaran ini meliputi ranah kognitif, afektif, dan psikomotor dengan menitikberatkan ranah afektif. Tugas untuk melaksanakan misi tersebut bukanlah hal yang mudah dan diperlukan suatu pembelajaran yang tepat agar misi yang diembannya dapat tercapai. Untuk menanamkan nilai-nilai yang dikehendaki ini tentu saja melalui proses pembelajaran yang benarbenar tepat bagi pembelajaran pendidikan nilai agar pembentukan kepribadian siswa dapat tercapai.

Dalam rangka mencapai tujuan bidang studi ini, para guru seharusnya telah menerapkan caracara pendidikan nilai pada kegiatan pengajaran di kelas. Namun pada kenyataannya, pembelajaran PKn di sekolah dasar belum menerapkan pembelajaran pendidikan nilai secara benar. Akibatnya pembelajaran nilai dan pembentukan kepribadian yang sesuai dengan nilai moral Pancasila hanya bersifat verbalisme saja, artinya anak didik hanya diberi pengetahuan tentang Pancasila bukan untuk diamalkan.

Berdasarkan pengamatan dan hasil diskusi dengan para guru di SDN 116881 Torgamda, guru belum menerapkan pembelajaran pendidikan nilai yang layak dalam pembelajaran PKn. Sementara itu, metode ceramah dan tanya jawab masih digunakan sangat dominan dalam menyampaikan bahan pelajaran, guru belum mendayagunakan model-model pembelajaran pendidikan nilai-moral. Padahal dalam kenyataannya banyak model pengajaran nilai moral yang dapat diterapkan oleh guru dalam menanamkan nilai moral Pancasila dalam rangka pembentukan kepribadian bangsa. Salah satu model pembelajaran yang bisa diterapkan dalam mata pelajaran PKn adalah model bermain peran.

Berdasarkan uraian diatas maka dapat dikemukakan permasalahannya: "Apakah kualitas pengajaran $\mathrm{PKn}$ dapat ditingkatkan dengan mengguna-kan model pembelajaran bermain peran?". Sedangkan yang menjadi tujuan penelitian ini adalah untuk (1) memperoleh gambaran mengenai cara guru dalam mengajarkan bidang studi PKn, (2) memberikan masukan bagi guru tentang pelaksanaan kegiatan mengajar bidang studi PKn dengan model pembelajaran bermain peran, (3) membantu guru agar lebih meningkatkan kualitas pembelajaran bidang studi PKn, dan (4) Membantu guru agar lebih mampu memanfaatkan model pengajaran nilaimoral pada pengajaran PKn.

Untuk mengaktifkan siswa dalam belajar optimal diperlukan strategi pembelajaran yang berbasis keaktifan siswa. Pembelajaran yang berbasis keaktifan menempatkan siswa sebagai titik sentral dalam pembelajaran, sementara peran guru adalah fasilitator, motivator dan dinamisator bagi siswa. Oleh karena itu guru harus mampu mengembankan strategi pembelajaran yang memacu keaktifan siswa dalam belajar pada setiap menyajikan materi pelajaran. Salah satu strategi pembelajaran yang dapat mengaktifkan siswa adalah strategi pembelajaran kooperatif tipe STAD.

Berdasarkan pengamatan peneliti sewaktu mengadakan survey ke SDN 116881 Torgamda, guru umumnya menerapkan strategi ekspositori di mana pembelajaran berpusat pada guru (teachercentred) dalam hal ini hasil yang dicapai sering tidak sesuai dengan yang diharapkan dan tidak semua siswa terlibat aktif.

Sudah selayaknya paradigm lama pembelajaran PKn diperbaiki. Pembelajaran sebaiknya ditekankan pada pengetahuan yang bermakna, guru diharapkan dapat mengubah strategi pembelajaran sehingga siswa merasa diikutsertakan dalam proses pembelajaran.

\section{Hakikat Belajar PKn}

Pendidikan Kewarganegaraan (PKn) adalah program pendidikan berdasarkan nilainilai pancasila sebagai wahana untuk mengembangkan dan melestarikan nilai luhur dan moral yang berakar pada budaya bangsa Indonesia yang diharapkan dapat menjadi jati diri yang diwujudkan dalam bentuk perilaku kehidupan sehari-hari. Maka pembelajaran PKn merupaka mata pelajaran yang memfokuskan pada pembentukan warga negara yang memahami dan mampu melaksanakan hak-hak dan kewajibannya untuk menjadi warga negara 
Indonesia yang cerdas, terampil, dan berkarakter yang diamanatkan oleh Pancasila dan UUD 1945 (Walfarianto \& Rejeki, 2009: 16-24).

Seperti halnya mata pelajaran yang lain, PKn juga memiliki tujuan untuk mengembangkan kemampuan peserta didik agar dapat tumbuh menjadi warga negara yang baik (good citizen). Sesuai dengan yang ditetapkan oleh Badan Standar Nasional Pendidikan (BSNP), tujuan mata pelajaran PKn adalah untuk memberikan kompetensi-kompetensi kepada siswa sebagai berikut menurut Wury \& Fathurohamn (2012: 9-10):

1. Berpikir secara kritis, rasional, dan kreatif dalam menaggapi isu kewarganegaraan.

2. Berpartisipasi secara bermutu dan bertanggung jawab, dan bertindak secara cerdas dalam kegiatan bermasyarakat, berbangsa, dan bernegara.

3. Berkembang secara positif dan demokratis untuk membentuk diri berdasarkan pada karakter-karakter masyarakat Indonesia agar dapat hidup bersama dengan bangsa-bangsa lainnya.

4. Berinteraksi dengan bangsa-bangsa lain dalam percaturan dunia secara langsung atau tidak langsung dengan memanfaatkan teknologi informasi dan komunikasi.

Dengan melihat tujuan mata pelajaran PKn di atas dapat disimpulkan bahwa di dalamnya memuat aspek kognitif, afektif, dan psikomotor. Untuk dapat mencapai tujuan mata pelajaran PKn tersebut secara maksimal, maka guru perlu menyusun strategi pembelajaran yang digunakan di kelas yang sesuai dengan masing-masing aspek pembelajaran.Mata pelajaran Pancasila dan Kewarganegaraan adalah mata pelajaran untuk mengembangkan moral serta meningkatkan mutu kehidupan dan martabat manusia Indonesia yang berkepribadian Indonesia sesuai dengan tujuan pendidikan nasional, sebagaimana yang di amanatkan dalam UU. RI No. 20 Tahun 2003, Tentang Sistem Pendidikan Nasional, bahwa Pendidikan Nasional bertujuan untuk berkembangnya potensi peserta didik agar menjadi manusia yang beriman dan bertakwa kepada Tuhan Yang Maha Esa, berakhlak mulia, sehat, berilmu, cakap, kreatif, mandiri, dan menjadi warga negara yang demokratis serta bertanggung jawab.

Untuk terwujudnya tujuan Pendidikan Nasional tersebut guru harus mampu dan siap untuk menanamkan nilai-nilai moral kepada diri siswa sebagai generasi penerus, agar memiliki kepribadian yang sesuai dengan tujuan pendidikan nasional dan berjiwa Pancasila.

Salah satu mata pelajaran di SD adalah PKn, "mata pelajaran PKn merupakan mata pelajaran untuk membentuk warga negara yang cerdas, terampil, dan berkarakter, setia kepada bangsa dan negara Indonesia dengan Amanat Pancasila dan UUD 1945". Mata pelajaran PKn diharapkan dapat mewujudkan proses pendidikan yang integral dan mampu mengembangkan kepribadian warga negara yang partisipatif bertanggung jawab yang pada gilirannya akan menjadi landasan untuk berkembanganya masyarakat Indonesia yang demokratis dan lebih mencintai tanah airnya serta tidak mudah dipecah belah sebagaimana terdapat dalam materi PKn kelas V Bab 1 tentang Menjaga Keutuhan Negara Indonesia.

\section{Hakikat Strategi Pembelajaran}

Hamalik (2001) mendefenisikan strategi pembelajaran adalah keseluruhan metode dan prosedur yang menitikberatkan pada kegiatan siswa dalam proses belajar mengajar untuk mencapai tujuan tertentu. Dalam konsteks strategi pembelajaran tersusun tujuan yang hendak dicapai, materi yang hendak dipelajari, pengalaman-pengalaman belajar dan prosedur evaluasi. Namun dalam penelitian ini yang akan diuji pengaruhnya terhadap hasil belajar PKn hanya strategi pembelajaran kooperatif tipe STAD dan strategi pembelajaran ekspositori .

\section{Hakikat Strategi Pembelajaran Kooperatif Tipe STAD (Student Teams Achievement Divisions)}

Istilah Cooperative learning dalam pengertian bahasa Indonesia dikenal dengan nama pembelajaran kooperatif. Penggunaan pembelajaran kooperatif tipe STAD (cooperative learning) merupakan suatu strategi dalam proses pembelajaran yang membutuhkan partisipasi dan kerjasama dalam kelompok. Pembelajaran koooperatif dapat meningkatkan cara kerja siswa menuju lebih baik, sikap tolong menolong dalam beberapa perilaku sosial. Lie (2004) menyebut cooperative learning dengan istilah pembelajaran gotong royong, yaitu system pembelajaran yang memberi kesempatan kepada peserta didik untuk bekerja sama dengan siswa lain dalam tugas tugas yang terstruktur. Lebih jauh dikatakan pembelajaran 
kooperatif hanya berjalan kalau sudah terbentuk suatu kelompok atau suatu tim yang didalamnya siswa bekerja secara terarah. Untuk mencapai tujuan yang sudah ditentukan dengan jumlah anggota kelompok pada umumnyaa terdiri dari 4-6 orang.

Strategi Kooperatip tipe STAD dikembangkan oleh Robert Slavin, dimana STAD merupakan pendekatan koperatif yang sederhana. Kinerja guru yang menggunakan STAD mengacu pada belajar kelompok, menyajikan informasi akademik baru pada siswa dengan menggunakan presentase verbal atau teks. Anggota tim menggunakan lembar kegiatan atau perangkat pembelajaran yang lain untuk menuntaskan materi pelajarannya, kemudian saling membantu satu sama lain untuk memahami bahan pelajaran melalui tutorial, kuis satu sama lain dan melakukan diskusi.

Teknik pembelajaran kooperatif lebih unggul dalam meningkatkan hasil belajar dibandingkan dengan pengalaman-pengalaman belajar individual (secara klasikal). Tugas-tugas yang kompleks seperti pemecahan masalah, berpikir kritis, dan pembelajaran konseptual meningkat secara nyata pada saat digunakan strategi-strategi kooperatif. Siswa lebih memiliki kemungkinan menggunakan tingkat berpikir yang lebih tinggi selama dan setelah diskusi dalam kelompok kooperatif daripada mereka bekerja secara individual. Akibatnya, materi yang dipelajari siswa akan melekat untuk periode waktu yang lebih lama (Ibrahim, dkk, 2000).

Dari uraian ini dapat disimpulkan bahwa strategi pembelajaran kooperatif tipe STAD adalah bertujuan untuk meningkatkan kemampuan siswa dalam menyelesaikan tugastugas akademik secara tim melalui serangkaian kegiatan yang mempertimbangkan aspek penilaian terhadap skor tim maupun skor individu dalam menguasai materi yang telah dibahas siswa secara bersama dalam tim, di bawah pengawasan guru.

\section{Hakikat Strategi pembelajaran Ekspositori}

Strategi pembelajaran ekspositori menekankan pada pembelajaran bertutur. Materi pelajaran sengaja diberikan secara langsung. Peran siswa dalam strategi ini adalah menyimak untuk menguasai materi pelajaran yang disampaikan guru. Aliran psikologi belajar yang sangat mempengaruhi strategi pembelajaran
Perilaku mengajar dengan strategi ekspositori merupakan kegiatan mengajar yang terpusat pada guru. Guru aktif memberikan penjelasan atau informasi terperinci tentang bahan pengajaran. Menurut Dimyati (2006) tujuan utama pembelajaran secara ekspositori adalah "memindahkan" pengetahuan, keterampilan, dan nilai-nilai kepada siswa. Hal yang esensiall pada bahan pengajaran harus dijelaskan kepada siswa. Selanjutnya Dimyati (2006) mengatakan "Adapun peranan guru yang paling penting adalah sebagai berikut: (i) penyusun program pembelajaran, (ii) pemberi informasi yang benar, (iii) pemberi fasilitias belajar yang baik, (iv) pembimbing siswa dalam pemerolehan informasi yang benar, dan (v) penilai pemerolehan informasi"

\section{Hakikat Komunikasi Interpersonal}

Menurut Roger sebagaimana dikutip Muhammad (2007) bahwa komunikasi interpersonal akan berjalan efektif apabila kedua belah pihak yang berkomunikasi memenuhi kondisi berikut: (1) bertemu satu sama lain secara personal, (2) empati secara tepat terhadap pribadi yang lain dan berkomunikasi yang dapat dipahami satu sama lain secara berarti, (3) menghargai satu sama lain, bersifat positif dan wajar tanpa menilai atau keberatan (4) menghayati pengalaman satu sama lain dengan sungguh-sungguh, bersikap menerima dan empati satu sama lain, (5) merasa bahwa saling menjaga keterbukaan dan iklim yang mendukung dan mengurangi kecenderungan gangguan arti, dan (6) memperlihatkan tingkah laku yang percaya penuh dan memperkuat perasaan aman terhadap yang lain. Devito sebagaimana dikutip Thoha (2003) menjelaskan bahwa komunikasi interpersonal akan efektif bila memenuhi aspekaspek: (1) keterbukaan, (2) empati, (3) dukungan, (4) kepositifan, dan (5) kesamaan. Menurut Cangara (1996) fungsi dari Komunikasi interpersonal adalah.(1) meningkatkan hubungan insani (human relations), (2) menghindari dan (3) mengatasi konflik-konflik pribadi, mengurangi ketidakpastian sesuatu, serta berbagi pengetahuan dan pengalaman dengan orang lain. Sehubungan dengan itu menurut Johnson dalam Safari (2005) menyatakan ada empat manfaat dari hubungan interpersonal bagi anak, yaitu (1) komunikasi interpersonal membantu perkembangan intelektual dan sosial anak, (2) identitas atau jati diri anakterbentuk dalam 
komunikasi dengan diri sendiri dan lewat komunikasi dengan orang lain, (3) dalam rangka memahami realitas di sekelilingnya, anak melakukan perbandingan social untuk memperoleh pemahaman akan dunia sekelilingnya, (4) kesehatan mental anak sebagian ditentukan oleh kualitas komunikasi atau hubungan antar pribadi yang terjalin antara anak terutama dengan orang-orang terdekatnya.

Berdasarkan teori-teori yang telah dikemukakan di atas, maka sub variabel dalam penelitian ini yang mau diukur adalah: bertemu satu sama lain secara personal, (2) empati secara tepat terhadap pribadi yang lain dan berkomunikasi yang dapat dipahami satu sama lain secara berarti, (3) menghargai satu sama lain, bersifat positif dan wajar tanpa menilai atau keberatan (4) menghayati pengalaman satu sama lain dengan sungguhsungguh, bersikap menerima dan empati satu sama lain, (5) merasa bahwa saling menjaga keterbukaan dan iklim yang mendukung dan mengurangi kecenderungan gangguan arti, dan (6) memperlihatkan tingkah laku yang percaya penuh dan memperkuat perasaan aman terhadap yang lain.

Hasil Penelitian Daulay (2009) mengemukakan bahwa siswa yang dengan karakteristik komunikasi interpersonal tinggi, strategi yang tepat digunakan adalah strategi pembelajaran kolaboratif dan siswa dengan karakteristik komunikasi interpersonal rendah, strategi yang tepat digunakan adalah strategi pembelajaran kompetitif. Implikasinya adalah penerapan strategi pembelajaran kompetitif dan kolaboratif harus disesuaikan dengan tinggi dan rendahnya tingkat komunikasi interpersonal.

Selanjutnya,

Nadeak

(2008)

megemukakan bahwa siswa yang memiliki kemampuan awal tinggi jika dibelajarkan dengan strategi pembelajaran inquiri akan memperoleh hasil belajar fisika siswa yang lebih tinggi dibandingkan jika dibelajarkan dengan strategi ekspositori. Akan tetapi siswa yang memiliki kemampuan awal yang rendah jika dibelajarkan dengan strategi pembelajaran ekspositori akan memperoleh hasil belajar fisika siswa yang lebih tinggi dibandingkan dengan jika dibelajarkan dengan strategi.

\section{Pengaruh Perbedaan komunikasi Interpersonal Terhadap Hasil belajar PKn}

Kemampuan berkomunikasi dalam diri siswa merupakan salah satu factor yang mempengaruhi kualitas belajar siswa. Siswa yang memiliki kemampuan komunikasi interpersonal yang tinggi mempunyai kemampuan bekerja yang baik, mampu mengontrol lingkungannya, dapat mengembangkan pengetahuannya, tanggap terhadap fenomena, dapat mengaplikasikan interaksi yang baik di lingkungannya.

Sedangkan siswa yang mempunya komunikasi interpersonal yang rendah memilki kemampuan yang kurang baik dalam bekerjasama, kurang mampu menyampaikan pesan atau makna yang terkandung dalam materi, tidak tanggap terhadap fenomena yang terjadi, kurang mampu memberi pendapat dan solusi terhadap persolan yang terjadi, cenderung hanya menerima dan mengikuti keputusan.

Dari uraian di atas, dapat diduga bahwa terdapat perbedaan hasil belajar PKn antara siswa yang mempunyai kemampuan komunikasi interpersonal tinggi dengan siswa yang memiliki kemampuan komunikasi interpersonal rendah.

\section{Interaksi Strategi Pembelajaran dan Komunikasi Interpersonal terhadap Hasil Belajar PKn}

Pemberian strategi pembelajaran kooperatif tipe STAD pada siswa yang mempunyai kemampuan komunikasi interpersonal yang tinggi akan mempunyai hasil yang lebih baik karena kemampuan komunikasi interpersonal yang tinggi akan mendorong siswa untuk mencari pengetahuan yang sebanyak-banyaknya dari berbagai sumber yang nantinya akan didiskusikan bersama sehingga siswa akan lebih kreatif menghubungkan materi-materi yang sudah dipelajari dan yang akan dipelajari. Siswa yang memiliki kemampuan komunikasi tinggi memberi peluang untuk bekerjasama dengan siswa lain dalam memecahkan masalah dan terbiasa dalam mengembangkan nalarnya sehingga pelajaran akan mudah diterima, sehingga hasil belajar akan maksimal

Pemberian strategi kooperatif tipe STAD pada siswa yang mempunyai kemampuan komunikasi interpersonal rendah akan mengakibatkan siswa merasa bosan karena tidak mampu bekerjasama dengan temannya. Situasi itu membuat siswa merasa diabaikan dan kadang hanya menunggu hasil yang dikerjakan temanya. Siswa yang memiliki komunikasi interpersonal rendah membutuhkan waktu dan proses pembelajaran yang lebih lama untuk memahami materi, sehingga kesulitan 
dalam menyelesaikan soal-soal yang dihadapi, karena pengetahuannya berdasarkan informasi yang disampaikan oleh guru dan tidak mampu mencari sendiri informasi karena terbiasa dengan pola menghapal sehingga hasil belajar PKn kurang maksimal.

Pemberian strategi pembelajaran ekspositori apabila diberikan kepada siswa yang memiliki komunikasi interpersonal tinggi akan menimbulkan kebosanan karena siswa hanya menerima dan menyimak materi yang disajikan oleh guru sehingga menekan daya nalar siswa yang dapat berakibat hasil belajar yang kurang maksimal.

Pemberian strategi pembelajaran ekspositori apabila diberikan pada siswa yang memiliki komunikasi interpersonal yang rendah akan memperoleh hasil belajar yang lebih baik, sebab siswa cenderung hanya menerima dan memahami makna pelajaran melalui yang disampaikan guru sesuai dengan tujuan instruksional yang sudah ditetapkan.

\section{METODE}

Penelitian ini akan dilaksanakan di SDN 116881 Torgamda. Populasi dalam penelitian ini adalah seluruh siswa kelas $\mathrm{V}$ SDN 116881 Torgamda yang terdiri dari 3 kelas pararel. Sampel akan diambil 2 kelas secara acak kelas (cluster random sampling). Pemilihan acak (cluster random sampling) ini dimungkinkan karena menurut wakil kepala sekolah bidang kurikulum pendistribusian siswa pada setiap kelas dilakukan secara acak.

Teknik pengumpulan data dilakukan untuk menguji hipotesis penelitian data yang dikelompokkan pada penelitian ini ada dua jenis yaitu menggunakan angket untuk komunikasi interpersonal dan menggunakan teknik tes untuk memperoleh hasil belajar PKn .

Instrumen angket digunakan untuk mengetahui komunikasi interpersonal sehingga dapat dikelompokkan atas komunikasi interpersonal tinggi dan rendah. Jumlah soal sebanyak 45 soal butir pertanyaan untuk mengukur indikator-indikator komunikasi interpersonal yang disusun berdasarkan kategori positif dan negatif adalah: selalu, sering, jarang, tidak pernah. Pernyataan positif diberi skor 4,3,2,1 sedangkan untuk pernyataan negatif: selalu, sering, jarang, tidak pernah diberi skor 1,2,3,4.

Desain penelitian yang digunakan adalah desain faktorial $2 \times 2$, seperti terlihat pada Tabel 1. yang mengelompokkan strategi
Mind Map dengan strategi pembelajaran ekspositori terhadap gaya belajar visual dan gaya belajar kinestetik.

Tabel 1. Desain Penelitian

\begin{tabular}{|l|c|c|}
\hline \multirow{2}{*}{$\begin{array}{c}\text { Tingkat } \\
\text { Komunikasi (B) }\end{array}$} & $\begin{array}{c}\text { Tipe STAD } \\
\left(\mathrm{A}_{1}\right)\end{array}$ & $\begin{array}{c}\text { Ekspositori } \\
\left(\mathrm{A}_{2}\right)\end{array}$ \\
\hline $\begin{array}{l}\text { Interpersonal } \\
\text { Tinggi }\left(\mathrm{B}_{1}\right)\end{array}$ & $\mathrm{A}_{1} \mathrm{~B}_{1}$ & $\mathrm{~A}_{2} \mathrm{~B}_{1}$ \\
\hline $\begin{array}{l}\text { Interpersonal } \\
\text { Rendah }\left(\mathrm{B}_{2}\right)\end{array}$ & $\mathrm{A}_{1} \mathrm{~B}_{2}$ & $\mathrm{~A}_{2} \mathrm{~B}_{2}$ \\
\hline
\end{tabular}

Keterangan :

$\mathrm{A}=$ Strategi pembelajaran

$\mathrm{B}=$ Tingkat Komunikasi

A $\quad=$ Strategi pembelajaran Tipe STAD

$\mathrm{A}_{2}=$ Strategi pembelajaran ekspositori

$\mathrm{B}_{1} \quad=$ Interpersonal Tinggi

$\mathrm{B}_{2}=$ Interpersonal Rendah

$\mathrm{A}_{1} \mathrm{~B}_{1}=$ Hasil belajar PKn siswa yang diajar dengan menggunakan strategi STAD pada siswa dengan komunikasi interpersonal tinggi

$\mathrm{A}_{1} \mathrm{~B}_{2}=$ Hasil belajar PKn siswa yang diajar dengan menggunakan strategi STAD pada siswa dengan komunikasi interpersonal rendah.

$\mathrm{A}_{2} \mathrm{~B}_{1}=$ Hasil belajar Teknologi Perkantoran siswa yang diajar dengan menggunakan strategi pembelajaran ekspositori pada siswa dengan komunikasi interpersonal tinggi.

$\mathrm{A}_{2} \mathrm{~B}_{2}=$ Hasil belajar Teknologi Perkantoran siswa yang diajar dengan menggunakan strategi pembelajaran ekspositori pada siswa dengan komunikasi interpersonal rendah.

\section{Teknik Analisis Data}

Teknik analisa data yang digunkan adalah teknik statistik deskriptip dan infrensial. Teknik statistik deskriptif digunakan untuk mendeskripsikan data penelitian dengan daftar distribusi frekwensi dan membuat histogram.. Dari data tersebut selanjutnya akan dihitung mean, modian, modus, varians dan simpangan baku. Teknik statistic infrensial digunakan untuk menguji hipotesis penelitian dengan menggunakan teknik analisis varians (ANAVA) 
dua jalur dengan taraf signifikansi 5\% ( $\mathfrak{a}=$ $0,05)$.

Sebelum hipotesis diuji terlebih dahulu dilakukan uji persyaratan analisis yaitu uji nomalitas dan homogenitas. Uji normalitas dengan menggunakn uji Liliefors. Hal ini dimaksudkan untuk mengetahui apakah data yang diteliti berdistribusi normal atau tidak. Uji homogenitas mengunakan uji Fisher dan uji Bartlett, hal ini dilakukan untuk melihat apakah data yang diperoleh memilki variasi yang homogeny atau tidak. Selanjutnya dalam pengujian hipotesis penelitian, maka hipotesis statistik dapat dinyatakan sebagai berikut:

Rumusan hipotesis statistik dalam penelitian ini adalah sebagai berikut:

a. Hipotesis pertama :

$$
\begin{array}{ll}
\text { Ho } & : \mu_{A 1} \leq \mu_{A 2} \\
\text { H1 } & : \mu_{A 1}>\mu_{A 2}
\end{array}
$$

b. Hipotesis kedua :

$$
\begin{array}{ll}
\text { Ho } & : \mu_{B 1} \leq \mu_{B 2} \\
\text { H1 } & : \mu_{B 1}>\mu_{B 2}
\end{array}
$$

c. Hipotesis ketiga :

Ho : $\mathrm{A} \times \mathrm{B}=0$

H1 : $\mathrm{A} \times \mathrm{B} \neq 0$

Keterangan :
$\mathrm{A}=$ Strategi pembelajaran
$\mathrm{B}=$ komunikasi interpersonal
$\mathrm{A}_{1}=$ Strategi pembelajaran STAD

$\mathrm{A}_{2}=$ Strategi pembelajaran ekspositori

$\mathrm{B}_{1}=$ komunikasi interpersonal tinggi

$\mathrm{B}_{2}=$ komunikasi interpersonal rendah

$\mu_{A 1}=$ Hasil belajar PKn siswa yang memperoleh pembelajaran dengan strategi $S T A D$

$\mu_{A 2}=$ Hasil belajar PKn siswa yang memperoleh pembelajaran dengan strategi pembelajaran ekspositori

$\mu_{B 1} \quad=$ Hasil belajar PKn siswa yang memiliki komunikasi interpersonal tinggi.

$\mu_{B 1} \quad=$ Hasil belajar PKn siswa yang memiliki komunikasi interpersonal rendah.

$\mathrm{A} \times \mathrm{B}=$ Interaksi antara strategi pembelajaran dengan komunikasi interpersonal.

\section{HASIL DAN PEMBAHASAN \\ Hasil}

Berdasarkan data skor tes hasil belajar PKn siswa, langkah berikutnya adalah menghitung total skor dan rata-rata skor tiap kelompok perlakuan menurut tabel ANAVA, yang selanjutnya dapat digunakan sebagai dasar

\begin{tabular}{|c|c|c|c|c|c|c|c|}
\hline \multirow{2}{*}{\multicolumn{2}{|c|}{ KS }} & \multicolumn{4}{|c|}{ Strategi Pembelajaran } & & \multirow[b]{2}{*}{ Total } \\
\hline & & \multicolumn{2}{|c|}{$\begin{array}{c}\text { Kooperatif tipe } \\
\text { STAD }\end{array}$} & \multicolumn{2}{|c|}{ Ekspositori } & & \\
\hline \multirow{2}{*}{ 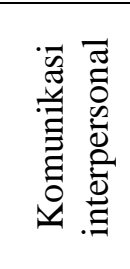 } & Tinggi & $\begin{array}{l}\mathrm{n} \\
\overline{\mathrm{X}} \\
\mathrm{Sd}\end{array}$ & $\begin{array}{l}=21 \\
=77.86 \\
=5.38\end{array}$ & $\frac{\mathrm{n}}{\mathrm{X}}$ & $\begin{array}{l}=19 \\
=75.60 \\
=5.52\end{array}$ & $\underset{S d}{\frac{n}{X}}$ & $\begin{array}{l}=40 \\
=76.76 \\
=5.57\end{array}$ \\
\hline & Rendah & $\begin{array}{l}\mathrm{n} \\
\mathrm{X} \\
\mathrm{Sd}\end{array}$ & $\begin{array}{l}=19 \\
=73.68 \\
=5.49\end{array}$ & $\frac{\mathrm{n}}{\mathrm{Sd}}$ & $\begin{array}{l}=18 \\
=68.50 \\
=5.77\end{array}$ & $\overline{\mathrm{Xd}}$ & $\begin{array}{l}=37 \\
=71.03 \\
=6.20\end{array}$ \\
\hline \multicolumn{2}{|c|}{ Total } & $\frac{\mathrm{n}}{\mathrm{X}}$ & $\begin{array}{l}=40 \\
=75.88 \\
=5.82\end{array}$ & $\begin{array}{l}\mathrm{n} \\
\mathrm{X} \\
\mathrm{Sd}\end{array}$ & $\begin{array}{l}=37 \\
=72.05 \\
=6.67\end{array}$ & $\underset{\mathrm{Sd}}{\mathrm{X}}$ & $\begin{array}{l}=77 \\
=73.96 \\
=6.54\end{array}$ \\
\hline
\end{tabular}
keputusan statistik untuk pengujian hipotesis, seperti pada Tabel 2 sebagai berikut:

Tabel 2. Hasil Statistik Deskriptif

\section{Pengujian Hipotesis}

Secara keseluruhan hasil Anava untuk pengujian hipotesis dapat dilihat pada Tabel 3 di bawah ini. 
Tabel 3. Rangkuman Hasil Anava Secara Keseluruhan Terhadap Hasil belajar PKn

\begin{tabular}{|l|c|c|c|c|c|}
\hline \multicolumn{1}{|c|}{ Sumber variasi } & $\mathrm{dk}$ & $\mathrm{JK}$ & $\mathrm{RJK}$ & $\mathrm{F}_{\text {hitung }}$ & $\begin{array}{c}\mathrm{F}_{\text {tabel(1.73) }} \\
(\alpha=0.05)\end{array}$ \\
\hline Strategi Pembelajaran & 1 & 656.36 & 656.36 & 140.85 & 3.98 \\
\hline Komunikasi Interpersonal & 1 & 292.62 & 292.62 & 62.79 & \\
\hline Interaksi & 1 & 21.44 & 21.44 & 4.60 & \\
\hline Galat Total & 73 & 354.47 & 4.66 & & \\
\hline \multicolumn{1}{|c|}{ T6 } & $\mathbf{1 3 2 4 . 8 9}$ & & & \\
\hline
\end{tabular}

Perbedaan Hasil belajar PKn Antara Siswa Yang Memperoleh Strategi pembelajaran kooperatif tipe STAD dan Ekspositori.

Adapun hipotesis statistik yang diuji adalah :

Ho $: \mu \mathrm{A} 1=\mu \mathrm{A} 2$

$\mathrm{Ha}: \mu \mathrm{A} 1>\mu \mathrm{A} 2$

Berdasarkan hasil pengujian hipotesis pada tabel 3 di atas, maka diperoleh hasil perhitungan data strategi pembelajaran, dimana $\mathrm{F}_{\text {hitung }}=140,85$, sementara nilai kritik $\mathrm{F}_{\text {tabel }}$ dengan $\mathrm{dk}=(1,73)$ dan $\alpha=0.05$ adalah sebesar 3.98. Hasil ini menunjukkan bahwa $\mathrm{F}_{\text {hitung }}=$ $140.85>\mathrm{F}_{\text {tabel }}=3.98$ sehingga Hipotesis Nol (Ho) ditolak, dengan demikian hipotesis penelitian yang menyatakan bahwa hasil belajar PKn siswa yang dibelajarkan dengan strategi pembelajaran kooperatif STAD lebih tinggi dari pada siswa yang diajarkan dengan strategi pembelajaran Ekspositori teruji kebenarannya.

\section{Perbedaan Hasil belajar PKn Antara Siswa Yang Memiliki Komunikasi interpersonal Tinggi Dan Rendah.}

Adapun hipotesis statistik yang diuji adalah :

Ho $: \mu \mathrm{B} 1=\mu \mathrm{B} 2$

$\mathrm{Ha}: \mu \mathrm{B} 1>\mu \mathrm{B} 2$

Berdasarkan hasil pengujian hipotesis pada Tabel 3 di atas diperoleh hasil perhitungan data komunikasi interpersonal, dimana $\mathrm{F}_{\text {hitung }}=$ 62.79 dan nilai kritik $\mathrm{F}_{\text {tabel }}$ dengan $\mathrm{dk}=(1,73)$ dan $\alpha=0.05$ adalah 3.98. Hasil ini menunjukkan bahwa $\mathrm{F}_{\text {hitung }}=62.79>\mathrm{F}_{\text {tabel. }}=$ 3.98 sehingga Hipotesis Nol (Ho) berhasil ditolak, dengan demikian hipotesis penelitian yang menyatakan bahwa siswa yang memiliki komunikasi interpersonal memperoleh hasil belajar Sosilogi yang lebih tinggi dari pada siswa yang memiliki komunikasi interpersonal rendah teruji kebenarannya.

Interaksi Antara Strategi Pembelajaran dan Komunikasi interpersonal Siswa Dalam Mempengaruhi Hasil belajar PKn

Adapun hipotesis statistik yang diuji adalah :

Ho : $\mathrm{A}><\mathrm{B}=0$

$\mathrm{Ha}: \mathrm{A}><\mathrm{B} \neq 0$

Berdasarkan hasil pengujian hipotesis di atas diperoleh perhitungan interaksi strategi pembelajaran dengan komunikasi interpersonal, dimana $\mathrm{F}_{\text {hitung }}=4.60$ dan nilai kritik $\mathrm{F}_{\text {tabel }}$ dengan $\mathrm{dk}=(1,73)$ dan $\alpha=0.05 \%$ adalah 3.98 . Hasil ini menunjukkan bahwa $F_{\text {hitung }}=4.60>$ $F_{\text {tabel. }}=3.98$ sehingga Hipotesis Nol $(\mathrm{Ho})$ ditolak. Karena telah berhasil menolak hipotesis nol dengan demikian hipotesis penelitian yang menyatakan bahwa terdapat interaksi antara strategi pembelajaran dan komunikasi interpersonal dalam memberikan pengaruh terhadap hasil belajar PKn teruji kebenarannya. Karena ada interaksi antara strategi pembelajaran dan komunikasi interpersonal dalam mempengaruhi hasil belajar PKn, maka perlu dilakukan uji lanjutan (post hoc test), untuk mengetahui rata-rata hasil belajar sampel mana yang berbeda. Untuk melihat bentuk interaksi antara strategi pembelajaran dan komunikasi interpersonal dalam mempengaruhi hasil belajar PKn, dilakukan uji lanjut dengan menggunakan uji Scheffe. Ringkasan hasil uji Scheffe dapat dilihat pada Tabel 4. berikut:

Tabel 4. Ringkasan Hasil Perhitungan Uji Scheffe'

\begin{tabular}{|c|c|c|c|}
\hline \multicolumn{2}{|c|}{ Hipotesis Statistik } & $\mathrm{F}_{\text {hitung }}$ & $\mathrm{F}_{\text {tabel }} ; \alpha=5 \%$ \\
\hline Ho $: \mu \mathrm{A}_{1} \mathrm{~B}_{1}=\mu \mathrm{A}_{2} \mathrm{~B}_{1}$ & Ho $: \mu \mathrm{A}_{1} \mathrm{~B}_{1}>\mu \mathrm{A}_{2} \mathrm{~B}_{1}$ & 4.97 & Ho $: \mu \mathrm{A}_{1} \mathrm{~B}_{1}=\mu \mathrm{A}_{2} \mathrm{~B}_{1}$ \\
\hline Ho $: \mu \mathrm{A}_{1} \mathrm{~B}_{2}=\mu \mathrm{A}_{2} \mathrm{~B}_{2}$ & Ho $: \mu \mathrm{A}_{1} \mathrm{~B}_{2}>\mu \mathrm{A}_{2} \mathrm{~B}_{2}$ & 13.88 & Ho: $\mu \mathrm{A}_{1} \mathrm{~B}_{2}=\mu \mathrm{A}_{2} \mathrm{~B}_{2}$ \\
\hline Ho $: \mu \mathrm{A}_{1} \mathrm{~B}_{1}=\mu \mathrm{A}_{1} \mathrm{~B}_{2}$ & Ho $: \mu \mathrm{A}_{1} \mathrm{~B}_{1}>\mu \mathrm{A}_{1} \mathrm{~B}_{2}$ & 6.12 & Ho: $\mu \mathrm{A}_{1} \mathrm{~B}_{1}=\mu \mathrm{A}_{1} \mathrm{~B}_{2}$ \\
\hline Ho $: \mu \mathrm{A}_{2} \mathrm{~B}_{1}=\mu \mathrm{A}_{2} \mathrm{~B}_{2}$ & Ho $: \mu \mathrm{A}_{2} \mathrm{~B}_{1}>\mu \mathrm{A}_{2} \mathrm{~B}_{2}$ & 10.40 & Ho: $\mu \mathrm{A}_{2} \mathrm{~B}_{1}=\mu \mathrm{A}_{2} \mathrm{~B}_{2}$ \\
\hline Ho $: \mu \mathrm{A}_{1} \mathrm{~B}_{1}=\mu \mathrm{A}_{2} \mathrm{~B}_{2}$ & Ho $: \mu \mathrm{A}_{1} \mathrm{~B}_{1}<\mu \mathrm{A}_{2} \mathrm{~B}_{2}$ & 2.78 & Ho: $\mu \mathrm{A}_{1} \mathrm{~B}_{1}=\mu \mathrm{A}_{2} \mathrm{~B}_{2}$ \\
\hline Ho $: \mu \mathrm{A}_{2} \mathrm{~B}_{1}=\mu \mathrm{A}_{1} \mathrm{~B}_{2}$ & Ho $: \mu \mathrm{A}_{2} \mathrm{~B}_{1}>\mu \mathrm{A}_{1} \mathrm{~B}_{2}$ & 7.43 & Ho $: \mu \mathrm{A}_{2} \mathrm{~B}_{1}=\mu \mathrm{A}_{1} \mathrm{~B}_{2}$ \\
\hline
\end{tabular}


Kriteria penerimaan jika : $\mathrm{F}_{\text {hitung }}>\mathrm{F}_{\text {tabel, }}$ maka teruji secara signifikan.

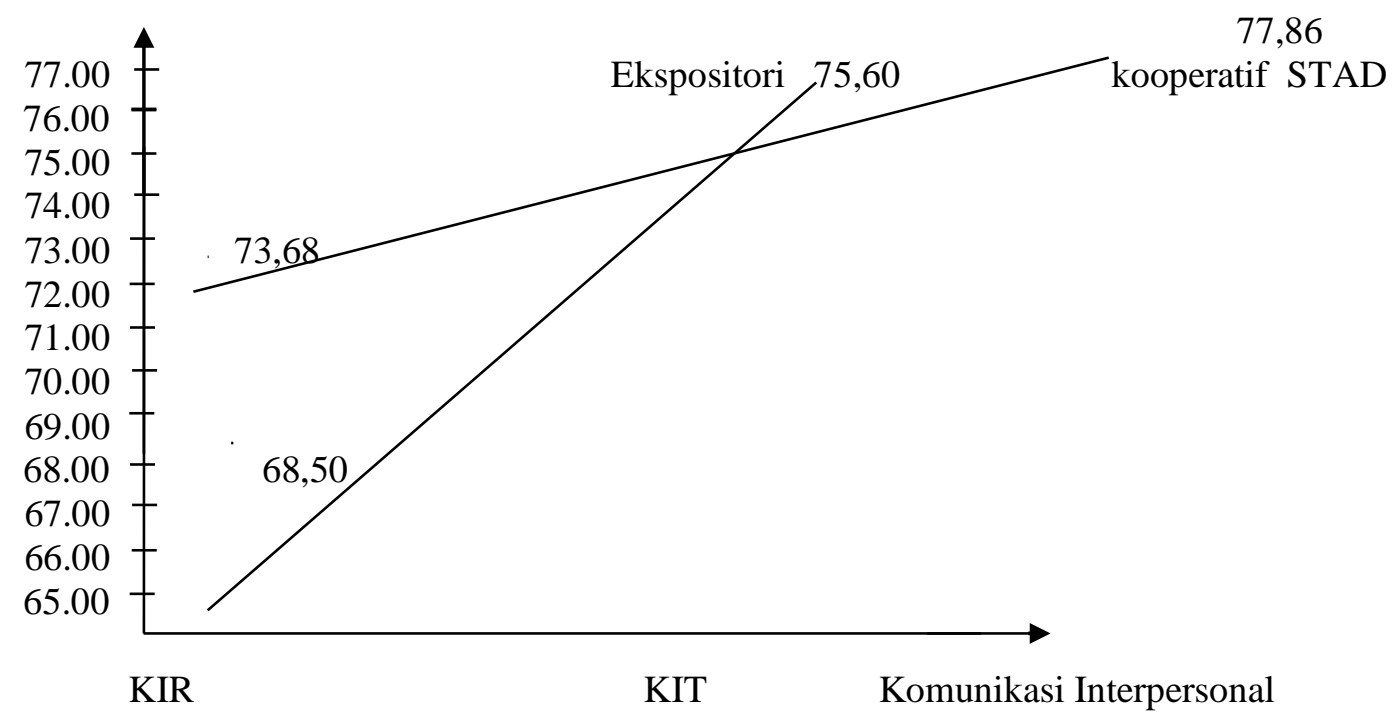

Gambar 1. Interaksi Antara Strategi Pembelajaran dan Komunikasi interpersonal Terhadap Hasil belajar PKn Siswa

\section{Pembahasan Hasil Penelitian}

Hasil penelitian ini telah menunjukkan bahwa hasil belajar PKn siswa SDN 116881 Torgamda yang diajar dengan strategi pembelajaran kooperatif tipe STAD lebih tinggi dibandingkan dengan strategi pembelajaran ekspositori. PKn merupakan mata pelajaran yang sangat penting untuk memupuk jiwa kemasyarakatan dan membekali siswa untuk dapat berinteraksi dengan baik terhadap masyarakat yang sama bahkan yang berbeda dengan latar belakang siswa sendiri. Serta diharapkan dengan belajar PKn siswa jurusan IPS mampu berkarya dan beradaptasi dengan baik di tengah-tengah masyarakat.

Dari uraian di atas, dapat dipahami bahwa mata pelajaran PKn sebenarnya merupakan mata pelajaran memiliki cakupan yang sangat luas, sehingga proses pembelajaran harus memberikan kesempatan kepada siswa untuk menanggapi materi pelajaran secara kritis, analitis agar nilai-nilai yang terkandung dalam mata pelajaran PKn betul-betul dipahami dan diyakini oleh siswa. Untuk itu, guru diharapkan memiliki pengetahuan dan pemahaman mengenai strategi pembelajaran, sebab pengetahuan dan pemahaman mengenai strategi pembelajaran sangat penting sebagai salah satu upaya dalam memberikan pengalaman dan pencapaian tujuan belajar yang optimal. Guru dituntut untuk meningkatkan mutu pembelajaran dan harus memperhatikan hakikat, tujuan pembelajaran yang akan diberikan.

Strategi pembelajaran kooperatif tipe STAD merupakan strategi pembelajaran kooperatif, dimana siswa belajar dalam kelompok kecil yang terdiri dari 4-6 orang secara heterogen dan bekerja sama saling ketergantungan yang positif dan bertanggungjawab atas ketuntasan bagian materi pelajaran yang harus dipelajari dan menyampaikan materi tersebut kepada kelompok yang lain (Arends, 2001).

Hasil penelitian ini telah menunjukkan bahwa siswa yang memiliki komunikasi interpersonal tinggi memperoleh nilai rata-rata hasil belajar PKn yang lebih baik dibandingkan dengan siswa yang memiliki komunikasi interpersonal rendah. Komunikasi interpersonal salah satu bentuk karakteristik siswa yang merupakan kemampuan untuk berinteraksi dengan orang lain dalam konteks sosial dengan cara-cara khusus yang dapat diterima oleh lingkungan dan pada saat bersamaan dapat menguntungkan individu, atau bersifat saling menguntungkan atau menguntungkan orang lain. Komunikasi interpersonal merupakan bagian dari kompetensi sosial. Komunikasi interpersonal sangat bermanfaat sebagai dasar dalam menentukan strategi pembelajaran yang sesuai sehingga dapat meningkatkan hasil belajar. 
Menurut Roger sebagaimana dikutip Muhammad (2007) bahwa komunikasi interpersonal akan berjalan efektif apabila kedua belah pihak yang berkomunikasi memenuhi kondisi berikut : (1) bertemu satu sama lain secara personal, (2) empati secara tepat terhadap pribadi yang lain dan berkomunikasi yang dapat dipahami satu sama lain secara berarti, (3) menghargai satu sama lain, bersifat positif dan wajar tanpa menilai atau keberatan (4) menghayati pengalaman satu sama lain dengan sungguh-sungguh, bersikap menerima dan empati satu sama lain, (5) merasa bahwa saling menjaga keterbukaan dan iklim yang mendukung dan mengurangi kecenderungan gangguan arti, dan (6) memperlihatkan tingkah laku yang percaya penuh dan memperkuat perasaan aman terhadap yang lain.

Siswa yang memiliki kemampuan komunikasi interpersonal yang tinggi akan memperlihatkan respons belajar yang berbeda dengan siswa yang memiliki komunikasi interpersonal yang rendah. Siswa yang memiliki komunikasi interpersonal yang tinggi mempunyai suatu kemampuan bekerja yang lebih baik, dibandingkan dengan siswa yang memiliki komunikasi interpersonal yang rendah. Siswa yang memiliki komunikasi interpersonal yang tinggi cenderung mampu untuk mengontrol lingkungannya, artinya melalui komunikasi interpersonal tersebut siswa dapat mengetahui peluang-peluang yang dapat dimanfaatkan dalam mendukung peningkatan belajarnya. Siswa dengan komunikasi interpersonal tinggi dapat melakukan berbagai hal yang dapat membuatnya untuk berbuat sesuatu yang lebih baik dalam memahami dengan memanfaatkan sumber-sumber belajar yang ada.

Sedangkan siswa yang memiliki komunikasi interpersonal rendah memiliki kemampuan yang kurang berbuat lebih baik dibandingkan dengan siswa yang memiliki komunikasi interpersonal. Siswa dengan komunikasi interpersonal rendah cenderung kurang mampu untuk menelaah dan mempelajari lebih mendalam lagi mengenai materi PKn yang artinya siswa tersebut tidak memiliki kemampuan untuk berprestasi dibandingkan dengan siswa yang lain. Sementara dalam mempelajari materi PKn seorang siswa dituntut untuk memiliki suatu hasrat atau keinginan dari dalam diri untuk berusaha, mencoba dan mencari lebih mendetail mengenai hal apa saja yang menyebabkan terjadinya suatu gejala dalam masyarakat. Sementara siswa yang memiliki komunikasi interpersonal rendah tidak memiliki ciri tuntutan tersebut, hal itu akan membawa akibat yang memungkinkan siswa tidak berusaha dan tidak aktif dalam belajar karena tidak ada komunikasi interpersonal dalam dirinya untuk mencapai suatu keberhasilan. Siswa yang memiliki komunikasi interpersonal rendah tidak banyak berbuat atau kurang respon dalam mempelajari materi PKn sehingga pada gilirannya hasil belajarnya kurang maksimal.

Berdasarkan uraian di atas, dapat dipahami bahwa siswa yang mempunyai komunikasi interpersonal tinggi memperoleh hasil belajar PKn yang lebih tinggi dibandingkan dengan siswa yag mempunyai komunikasi interpersonal rendah.

Dengan melihat luasnya cakupan dan objek PKn, maka dibutuhkan siswa yang mampu untuk membangun atau mengkonstruk sendiri pengetahuan dan komunikasi yang dibutuhkan untuk memecahkan masalahmasalah belajarnya. Di samping itu siswa harus menemukan sendiri pengetahuan tersebut, dan bukan karena diberitahukan oleh orang lain maupun gurunya. Siswa mampu belajar secara aktif dan mandiri dengan mengembangkan atau menggunakan gagasan-gagasan dalam menyelesaikan masalah pembelajaran. Dengan demikian, pengetahuan akan dapat diingat dan dipahami dalam memori jangka panjang, dan sewaktu-waktu dapat digunakan sesuai dengan kebutuhan belajar siswa.

Untuk siswa yang memiliki kemampuan komunikasi interpersonal tinggi, akan memberikan hasil belajar yang lebih baik jika diajarkan dengan strategi pembelajaran kooperatif Tipe STAD, sebab kemampuan komunikasi interpersonal yang tinggi biasaya terbiasa untuk mengungkapkan apa yang diketahuinya secara komunikatif kepada orang lain materi-materi pelajaran yang telah dipelajari dengan materi-materi pelajaran yang akan dipelajari. Melalui kemampuan komunikasi interpersonal yang tinggi, siswa berlomba dengan siswa lainnya dalam memecahkan masalah pembelajarannya, sehingga siswa akan terbiasa dalam mengembangkan daya nalarnya dalam mengembangkan materi pembelajaran yang telah disajikan guru, dan pada akhirnya materi itu dapat dengan mudah dikuasainya untuk memperoleh hasil belajar yang lebih maksimal. 


\section{PENUTUP}

Berdasarkan hasil penelitian dan pembahasan yang dikemukakan sebelumnya, maka dapat simpulkan bahwa :

1. Hasil belajar PKn siswa dengan strategi pembelajaran kooperatif STAD lebih baik dibandingkan dengan strategi pembelajaran Ekspositori. Dalam hal ini siswa yang dibelajarkan dengan menggunakan strategi pembelajaran kooperatif tipe STAD lebih baik dibandingkan dengan hasil belajar siswa yang dibelajarkan dengan strategi pembelajaran Ekspositori.

2. Hasil belajar siswa yang memiliki komunikasi interpesonal tinggi lebih baik dibandingkan dengan hasil belajar siswa yang memiliki komunikasi interpersonal rendah. Dengan demikian siswa yang memiliki komunikasi interpersonal tinggi memperoleh hasil belajar PKn yang lebih baik dibandingkan dengan siswa yang memiliki komunikasi interpersonal rendah

3. Terdapat interaksi antara strategi pembelajaran dengan komunikasi interpersonal dalam mempengaruhi hasil belajar PKn. Untuk siswa yang memiliki komunikasi interpersonal tinggi akan lebih efektif dalam meningkatkan hasil belajar PKn jika menggunakan strategi pembelajaran kooperatif tipe STAD, sedangkan untuk siswa yang memiliki komunikasi interpersonal rendah lebih efektif dalam meningkatkan hasil belajar PKn dengan menggunakan strategi pembelajaran ekspositori.

\section{DAFTAR PUSTAKA}

Arends, R.I. 2001. Learning to Teach, Fifth Edition. New York: Graw-Hill company

Cangara, H. (2004). Pengantar Ilmu

Komunikasi, cetakan V. Jakarta: Raja Grafindo.

Daulay, P Jamil (2009). Pengaruh Strategi Pembelajaran dan Komunikasi Interpersonal Terhadap Hasil Belajar Fisika Siswa SMP Negeri 1 Medan: Tesis PPS Unimed

Departemen Pendidikan Nasional. (2005).
Materi Pelatihan Terintegrasi Ilmu Pengetahuan Sosial . Jakarta: Dep. Pendidikan Nasional

Dimyati dan Moedjiono (1999). Belajar dan Pembelajaran. Jakarta : Rineke Cipta.

Efendi, OC (1984). Ilmu Komunikasi, Bandung : Rosdakarya.

Gagne, R.M. \& Briggs, L.J. (1979). Principles of Intructional Design. New York: Holt Rinehart and Winston.

Gagne, R.M. (1985). The Condition of Learning and The Theory of Intruction (4 th Edition). New York: Holt Rinehart and Winston.

Hamalik, O. (2001). Perencanaan Pengajaran Berdasarkan Pendekata Sistem. Jakarta: Bumi Aksara.

Ibrahim, M, dkk. (2000). Pembelajaran Kooperatif. Surabaya: university Press.

Lie, A. (2004). Cooperative Lerning: Mempraktikkan Cooperative Learning di ruang-ruang kelas. Jakarta. Grasind

Moehammad, A. (2007). Komunikasi Organisasi. Jakarta: Bumi Aksara.

Nadeak, I. Salam (2008). Pengaruh Strategi Pembelajaran dan Kemampuan Awal terhadap Hasil Belajar Fisika Siswa Sekolah Menengah Atas (SMA) Negeri 1 Binjai: Tesis PPS Unimed

Presiden RI. (2003). Undang-Undang Republik Indonesia No. 20 tahun 2003 tentang Sistem Pendidikan Nasional. Jakarta: Armas Duta Jaya

Safaria, T. (2005) Interpersonal Intelligence: Metode Pengembangan Kecerdasan Interpersonal Anak. Yogyakarta: Amara Books

Thoha, M. (2003) Prilaku Organisasi. Konsep Dasar dan Aplikasi. Jakarta: Rajagrafindo persada.

Walfarianto \& Sri Rejeki. (2009). Pendidikan $P K n$ SD. Yogyakarta: Universitas PGRI Yogyakarta.

Wuri Wuryandani \& Fathurrohman.( 2012). Pembelajaran Pendidikan Kewarganegaraan Di Sekolah Dasar. Yogyakarta: Ombak. 